\title{
Determination of knowledge levels of nurses and the factors affecting the level of knowledge in central venous catheter care
}

\author{
Sümeyye Aydoğdu*1, Meftun Akgün ${ }^{2}$ \\ ${ }^{1}$ Dr. Sami Ulus Maternity and Children's Health and Diseases Training and Research Hospital, Turkey \\ ${ }^{2}$ Üsküdar University, Faculty of Health Sciences, Nursing Department, Turkey
}

Received: February 12, 2020

Accepted: April 5, 2020

Online Published: April 16, 2020

DOI: $10.5430 /$ cns.v8n2p1

URL: https://doi.org/10.5430/cns.v8n2p1

\begin{abstract}
Objective: This study aimed to evaluate the catheter care given to patients with an inserted central venous catheter in the light of protocols and evidence-based applications.

Methods: The universe of the study consisted of 300 nurses working in the surgical and internal medicine units of the Health Sciences University Sultan Abdülhamid Han Training and Research Hospital. Although we planned to reach the whole universe in the sample, a total of 202 nurses were included in the study because 60 nurses left the hospital due to appointment to other provinces, and 38 nurses did not want to participate in the study. Data were collected using the face-to-face interview method through a questionnaire form designed by the researcher.

Results: Of the 202 nurses included in the study, 183 (90.6\%) were female, and 146 (72.3\%) had an undergraduate degree. Nurses who had received information about central venous catheter before and who were aware of the existence of a proto$\mathrm{col} /$ procedures/instructions about central venous catheter in the institution were found to get significantly high scores from correct answers that they gave to questions about central venous catheter $(p=.001, p=.035)$

Conclusions: To provide effective central venous catheter care, nurses should have information about the changing and developing care as well as good theoretical knowledge by following current research. In-service training programs in this area should be planned for nurses, and nurses should participate in activities such as congresses, seminars, and courses.
\end{abstract}

Key Words: Central venous catheter, Nursing, Care, Infection

\section{INTRODUCTION}

Central Venous Catheter (CVC) is a system containing a catheter inserted in the central venous access in operating rooms, intensive care units, and clinical units. Although CVC is the main application of the modern clinical treatment, it is the most commonly utilized catheter other than Peripheral Venous Catheters (PVC). ${ }^{[1]} \mathrm{CVC}$ is used for monitorization, long-term fluid replacement, long-term total parenteral nutrition (TPN), drug administration, injecting venous sclerosing agent, and transfusion of blood and blood products. ${ }^{[2]}$ In addition to its insertion into obese, edematous, or oncological patients with poor surface vein anatomy, it is also applied in cases where bedside PVC cannot be inserted. ${ }^{[3]}$

In addition to the advantages of $\mathrm{CVC}$, it may lead to artery in-

\footnotetext{
*Correspondence: Sümeyye Aydoğdu; Email: s.aydogdu91@ hotmail.com; Address: Dr. Sami Ulus Maternity and Children’s Health and Diseases Training and Research Hospital, Turkey.
} 
jury, fibrin sheath formation-bound dysfunction, hematoma, pneumothorax or the life-threatening air and catheter emboli. The most critical and feared complication that can develop due to CVC insertion is systemic or local infection. Radiological, microbiological, and biochemical examinations administered to the patient due to infection increase the length of hospital stay, and antibiotics and other medication used cause additional costs. ${ }^{[3-5]}$

In the literature, studies report that more than five million patients in the United States need CVC insertion each year, in 3\%-8\% of the catheters inserted, Central Catheter-Related Bloodstream Infection (CCRBI) develops, the cost associated with infection ranges between $\$ 300$ million and $\$ 2.3$ billion a year, and that the rate of mortality is between $12 \%$ and $25 \% .{ }^{[6]}$ In a study conducted in 19 hospitals and 41 intensive care units in Canada to determine the rate of CCRBI and risk factors for infection, the rate of CCRBI was determined as $6.9 \%$ in patients with inserted $\mathrm{CVC}^{\left[{ }^{[7]}\right.}$

Although the insertion of CVC in our country is under the duty, authority, and responsibility of the physician, the nurse is primarily responsible for its care after the catheter is inserted. Therefore, proper care given by the nurse affects the rate of development of infections and other complications related to the catheter. The proactive approach in nursing is protection. Therefore, nurses have a considerable share in/contribution to the prevention of catheter infection development. ${ }^{[3]}$ To prevent or reduce CCRBI as much as possible, the provision of appropriate and effective CVC care is an indication of quality nursing care.

This study was planned to evaluate the catheter care given to patients with an inserted CVC in the light of hospital protocols and evidence-based applications, and to determine the knowledge levels and practices of nurses on this subject.

\section{MATERIALS AND METHODS}

\subsection{Type of the study}

This study used a descriptive design and was carried out between 1 March 2018 and 5 June 2018 in the surgical and internal medicine bed units of the Health Sciences University Sultan Abdülhamid Han Training and Research Hospital.

\subsection{The universe and the sample}

There were 300 nurses working in the surgical and internal medicine bed units of the Health Sciences University Sultan Abdülhamid Han Training and Research Hospital, where CVC care could be given. Our study intended to reach all of this number. The sampling included 202 nurses because 60 nurses left the hospital due to interprovincial appointments, and 38 nurses did not want to participate in the study.

\subsection{Data collection tools}

The data of the study were collected through a questionnaire designed after a comprehensive literature review by the researcher.

The questionnaire was evaluated after taking the opinions of three experts before its administration, and a pilot study was conducted in a group of 9 people to test whether the questions were eligible and clear. Three questions that were difficult to understand were revised. The pilot study also functioned as a preliminary assessment to estimate the time required to collect the data, as well as helping the researcher to make a plan for fieldwork.

The questionnaire was administered by the researcher using face-to-face interview technique since the questionnaire was designed as a knowledge test to measure the knowledge of nurses, and there were differences among nurses in terms of their education levels such as health vocational school (4 years of high school education), associate degree (2 years of university education), undergraduate degree (4 years of university education) and graduate degree. Each interview took about 10-15 minutes. The questionnaire form consisted of two parts.

The 1st part was the "Nurse Information Form" and included the socio-demographic characteristics of the nurses (age, gender, marital status, education status, professional seniority, the department).

The 2nd part included "Nurses' Knowledge Levels Regarding CVC and their Catheter Care Practices" and consisted of 13 questions. These questions were designed in line with hospital protocols and evidence-based applications. The second part provides a wide-angle view of CVC care in terms of effectiveness and awareness as it also includes questions such as how nurses make dressings in their CVC-related care, frequency of dressing change, how often the sets used are changed, and techniques of blood sampling from the catheter and flushing the lumen of the catheter. Each correct answer was assigned 1 point, while each incorrect answer was assigned 0 points. Accordingly, the total score for the CVC-related level of knowledge was obtained from 13 questions. The lowest score was 0 , and the highest score was 13 , and for the sake of clarity, the total score of each case was evaluated by converting it into a grading scale from 0 to 100 . Accordingly, the score obtained ranged from 0 to 100 .

\subsection{Data analysis}

In the analysis of the data, NCSS (Number Cruncher Statistical System) 2007 (Kaysville, Utah, USA) software package was used. Student's t-test was employed to compare two groups of normally distributed variables, and the One-Way 
ANOVA test was used to compare three or more normally distributed groups. Also, Pearson's chi-square test was used to compare qualitative variables. Significance was evaluated at the level of $p<.05$.

\subsection{Ethics of the study}

At the outset, the approval of the Research Ethics Committee of Üsküdar University, the institutional approval of the Health Sciences University Sultan Abdülhamid Han Training and Research Hospital, and the written and verbal consents of the nurses involved in the study were obtained.

\section{RESUlts}

This study, which was conducted to determine the knowledge level and practices of nurses for CVC care in patients, found no significant difference between CVC knowledge score obtained by the nurses and their gender, education level, professional seniority, and the seniority in the current department. Nurses who had already received information about CVC and worked in the internal intensive care unit were found to have higher CVC knowledge scores (see Table 1).

Nurses' responses to the question, "What is applied to the skin after CVC dressing is cleaned with an antiseptic solution?" indicated that $7.9 \%(\mathrm{n}=16)$ responded "a transparent chlorhexidine gluconate-impregnated pad", which is the correct answer. On the other hand, $77.2 \%(n=156)$ of the nurses were observed to respond to the question, "Which handwashing method do you use while giving care to a patient with CVC?" with the correct option, "Hygienic handwashing" (see Table 2).

Table 1. Comparison of individual characteristics of the nurses by their $\mathrm{CVC}$ care knowledge scores $(\mathrm{N}=202)$

\begin{tabular}{|c|c|c|c|c|c|}
\hline \multirow{2}{*}{ Individual characteristics } & \multirow{2}{*}{$\mathbf{n}$} & \multirow{2}{*}{$\%$} & \multicolumn{2}{|c|}{ CVC care knowledge scores } & \multirow{2}{*}{$p$} \\
\hline & & & Min.-Max. & Mean $\pm S D$ & \\
\hline \multicolumn{6}{|l|}{ Gender } \\
\hline - Female & 183 & 90.6 & $7.69-84.62$ & $42.41 \pm 15.44$ & \multirow{2}{*}{.198} \\
\hline - Male & 19 & 9.4 & $15.38-61.54$ & $37.65 \pm 13.54$ & \\
\hline \multicolumn{6}{|l|}{ Educational status } \\
\hline $\begin{array}{l}\text { - Health Vocational High School - } \\
\text { Associate Degree }\end{array}$ & 15 & 7.4 & $23.08-69.23$ & $48.21 \pm 16.31$ & \multirow{3}{*}{.203} \\
\hline - Undergraduate & 146 & 72.3 & $15.38-84.62$ & $41.04 \pm 14.88$ & \\
\hline - Graduate & 41 & 20.3 & $7.69-84.62$ & $42.96 \pm 16.22$ & \\
\hline \multicolumn{6}{|l|}{ Department } \\
\hline - Surgical clinics & 59 & 29.1 & $7.69-76.92$ & $36.51 \pm 12.58$ & \multirow{4}{*}{$.001^{*}$} \\
\hline - Surgical intensive care & 30 & 14.9 & $23.08-84.62$ & $54.36 \pm 16.65$ & \\
\hline - Internal clinics & 90 & 44.6 & $15.38-69.23$ & $37.61 \pm 11.09$ & \\
\hline - Internal intensive care & 23 & 11.4 & $15.38-84.62$ & $56.86 \pm 16.19$ & \\
\hline \multicolumn{6}{|l|}{ Previous CVC knowledge } \\
\hline - Yes & 124 & 61.4 & $7.69-84.62$ & $45.29 \pm 16.21$ & \multirow{2}{*}{.001} \\
\hline - No & 78 & 38.6 & $15.38-69.23$ & $36.69 \pm 12.08$ & \\
\hline \multicolumn{6}{|l|}{ Professional seniority (years) } \\
\hline$\bullet<1$ & 60 & 29.7 & $15.38-69.23$ & $38.85 \pm 14.47$ & \multirow{5}{*}{.473} \\
\hline - $2-5$ & 60 & 29.7 & $15.38-84.62$ & $45.13 \pm 16.48$ & \\
\hline - $6-10$ & 15 & 7.4 & $38.46-69.23$ & $51.79 \pm 10.27$ & \\
\hline - $11-15$ & 19 & 9.4 & $15.38-69.23$ & $38.46 \pm 13.81$ & \\
\hline$\bullet>16$ & 48 & 23.8 & $7.69-69.23$ & $40.22 \pm 15.16$ & \\
\hline \multicolumn{6}{|c|}{ Seniority in the current department (years) } \\
\hline$\bullet<1$ & 117 & 57.9 & $15.38-84.62$ & $41.81 \pm 15.56$ & \multirow{4}{*}{.427} \\
\hline - $2-5$ & 56 & 27.8 & $7.69-84.62$ & $43.54 \pm 15.68$ & \\
\hline - $6-10$ & 16 & 7.9 & $23.08-69.23$ & $42.31 \pm 14.32$ & \\
\hline - > 11 & 13 & 6.4 & $15.38-61.54$ & $36.09 \pm 12.32$ & \\
\hline
\end{tabular}

Note. ${ }^{*}$ Statistically significant at $p<.05$ 
Table 2. Distribution of answers to questions regarding CVC care $(\mathrm{N}=202)$

\begin{tabular}{|c|c|c|}
\hline & $\mathbf{n}$ & $\%$ \\
\hline \multicolumn{3}{|l|}{ What is applied to the skin after CVC dressing is cleaned with an antiseptic solution? } \\
\hline Medical gauze & 64 & 31.7 \\
\hline Semi-permeable pad & 7 & 3.5 \\
\hline A transparent chlorhexidine gluconate-impregnated pad ${ }^{*}$ & 16 & 7.9 \\
\hline \multicolumn{3}{|l|}{ How often do you change the dressing if there is no contamination in the CVC dressing? } \\
\hline Every two days & 80 & 39.6 \\
\hline Every five days & 7 & 3.5 \\
\hline Every seven days* & 78 & 38.6 \\
\hline Every day & 37 & 18.3 \\
\hline \multicolumn{3}{|l|}{ Which of the antiseptic solutions used in CVC dressings is most effective? } \\
\hline Alcohol & 3 & 1.5 \\
\hline Povidone iodine & 78 & 38.6 \\
\hline $2 \%$ chlorhexidine ${ }^{*}$ & 105 & 52.0 \\
\hline Povidone iodine + Alcohol & 16 & 7.9 \\
\hline \multicolumn{3}{|l|}{ Which handwashing method do you use while giving care to a patient with CVC? } \\
\hline Hygienic handwashing ${ }^{*}$ & 156 & 77.2 \\
\hline Surgical handwashing & 35 & 17.3 \\
\hline I do not wash my hands, instead, I use micro-bactericidal hand disinfectant & 2 & 1.0 \\
\hline \multicolumn{3}{|l|}{ How many cm of area do you clean when doing CVC dressing? } \\
\hline $2 \mathrm{~cm}$ & 7 & 3.5 \\
\hline $3 \mathrm{~cm}$ & 26 & 12.9 \\
\hline $5 \mathrm{~cm}^{*}$ & 114 & 56.4 \\
\hline An area larger than $5 \mathrm{~cm}$ & 55 & 27.2 \\
\hline \multicolumn{3}{|l|}{ How often do you wash an intermittent CVC? (hours) } \\
\hline 48 & 17 & 8.4 \\
\hline $24^{*}$ & 75 & 37.1 \\
\hline 12 & 48 & 23.8 \\
\hline 8 & 62 & 30.7 \\
\hline \multicolumn{3}{|l|}{ How do you administer TPN solutions through the CVC lumen? } \\
\hline I spare one lumen only for this operation. & 109 & 54.0 \\
\hline I spare any of the lumens for this operation. & 44 & 21.8 \\
\hline I prepare a heparin solution and use $2 \mathrm{cc}$ to flush it. & 58 & 28.7 \\
\hline I prepare a heparin solution and use $5 \mathrm{cc}$ to flush it. & 66 & 32.7 \\
\hline I use single-use washing solutions for each lumen $(\mathrm{NaCl})^{*}$ & 58 & 28.7 \\
\hline I wash lumens with a single injector fluid drawn from $\mathrm{NaCl}$ solution. & 20 & 9.9 \\
\hline \multicolumn{3}{|l|}{ Which method do you use when taking blood sample from CVC? } \\
\hline $\begin{array}{l}\text { The first blood sample taken should be discarded, and the lumen should be washed with a heparinized } \\
\text { solution and then closed after collecting blood at once. }\end{array}$ & 114 & 56.4 \\
\hline Samples should be drawn one at a time, not at once. & 1 & 0.5 \\
\hline I do not think that the catheter should be washed before drawing the sample. & 1 & 0.5 \\
\hline $\begin{array}{l}\text { The first blood sample taken should be discarded, and the lumen should be washed with } \mathrm{NaCl} \text { solution } \\
\text { after drawing the blood at once. }\end{array}$ & 86 & 42.6 \\
\hline \multicolumn{3}{|l|}{$\begin{array}{l}\text { How often should blood and blood product transfusion sets or infusion sets used for patients whose } \\
\text { lipid emulsions are not supplied be changed in CVCs? }\end{array}$} \\
\hline In an interval of shorter than 24 hours & 111 & 55.0 \\
\hline In an interval of shorter than 48 hours & 29 & 14.3 \\
\hline In an interval of shorter than 72 hours & 54 & 26.7 \\
\hline In an interval of shorter than 96 hours $^{*}$ & 8 & 4.0 \\
\hline \multirow{2}{*}{\multicolumn{3}{|c|}{$\begin{array}{l}\text { How often should blood and blood product transfusion sets or infusion sets used for patients whose } \\
\text { lipid emulsions are given be changed in CVCs? }\end{array}$}} \\
\hline & & \\
\hline 12 hours & 94 & 46.5 \\
\hline 24 hours $^{*}$ & 96 & 47.5 \\
\hline 48 hours & 7 & 3.5 \\
\hline 72 hours & 5 & 2.5 \\
\hline \multicolumn{3}{|l|}{ How often should infusion sets which are used for propofol in CVCs be changed? } \\
\hline 6-12 hours ${ }^{*}$ & 108 & 53.5 \\
\hline 12-24 hours & 64 & 31.6 \\
\hline 24-48 hours & 24 & 11.9 \\
\hline 48-72 hours & 6 & 3.0 \\
\hline \multicolumn{3}{|l|}{ When should CVC be removed? } \\
\hline In applications longer than 6 weeks & 93 & 46.0 \\
\hline After 7 days & 28 & 13.9 \\
\hline After 14 days ${ }^{*}$ & 36 & 17.8 \\
\hline
\end{tabular}


Also, the responses of the nurses given to the question, "How often should blood and blood product transfusion sets or infusion sets used for patients whose lipid emulsions are not supplied be changed in CVCs?" indicated that $4 \%(\mathrm{n}=8)$ had supplied the correct answer, "In an interval of shorter than 96 hours" (see Table 2).

The findings indicated that there was a significant difference between the education level of nurses and the status of their participation in congress/course/seminar $(p=.019)$ and that congress/course/seminar participation rates of nurses who were health vocational high school-associate degree graduates was higher than nurses who had undergraduate or graduate degree (see Table 3 ).

The nurses who knew that their institution had a CVC proto$\mathrm{col} /$ procedures/instructions were found to get significantly higher scores from correct answers that they gave to CVC related questions than those who did not $(p=.035$, see Table 4).

Table 3. Comparison of the method of receiving CVC information by the level of education $(\mathrm{N}=202)$

\begin{tabular}{|c|c|c|c|c|c|}
\hline & & \multicolumn{3}{|c|}{ Level of education } & \multirow{3}{*}{$p$} \\
\hline & & $\begin{array}{l}\text { Health vocational high } \\
\text { school-associate degree }\end{array}$ & Undergraduate & Graduate & \\
\hline & & $\mathbf{N}(\%)$ & $\mathbf{N}(\%)$ & $\mathbf{N}(\%)$ & \\
\hline \multirow{2}{*}{ Receiving CVC information } & Yes & $10(66.7)$ & $88(60.3)$ & $26(63.4)$ & \multirow{2}{*}{.324} \\
\hline & No & $5(33.3)$ & $58(39.7)$ & $15(36.6)$ & \\
\hline \multirow{2}{*}{ Attending in-service training } & Yes & $6(60.0)$ & $55(62.5)$ & $20(76.9)$ & \multirow{2}{*}{.372} \\
\hline & No & $4(40.0)$ & $33(37.5)$ & $6(23.1)$ & \\
\hline \multirow{2}{*}{$\begin{array}{l}\text { Participation in congresses/ } \\
\text { courses/seminars }\end{array}$} & Yes & $10(100)$ & 78 (88.6) & $18(69.2)$ & \multirow{2}{*}{$.019^{*}$} \\
\hline & No & $0(0)$ & $10(11.4)$ & $8(30.8)$ & \\
\hline \multirow{2}{*}{ Self-learning } & Yes & $4(40.0)$ & $36(40.9)$ & $10(38.5)$ & \multirow{2}{*}{.975} \\
\hline & No & $6(60.0)$ & $52(59.1)$ & $16(61.5)$ & \\
\hline
\end{tabular}

Note. ${ }^{*}$ Statistically significant at $p<.05$

Table 4. CVC care knowledge score by awareness of the existence of a CVC protocol/procedures/instructions in the institution $(\mathrm{N}=202)$

\begin{tabular}{|c|c|c|c|c|}
\hline \multirow{2}{*}{$\begin{array}{l}\text { Existence of a CVC protocol/procedures/ } \\
\text { instructions in the institution }\end{array}$} & \multicolumn{3}{|c|}{ CVC Knowledge score } & \multirow{2}{*}{$p$} \\
\hline & $\mathbf{N}$ & Min.-Max. & Mean $\pm S D$ & \\
\hline Yes & 144 & $7.69-84.62$ & $43.38 \pm 15.24$ & \multirow{2}{*}{$.035^{*}$} \\
\hline No & 57 & $15.38-84.62$ & $38.33 \pm 15.14$ & \\
\hline
\end{tabular}

Note. ${ }^{*}$ Statistically significant at $p<.05$

\section{Discussion}

The most serious complication that can develop after the insertion of CVC is infection, which threatens patients' life and leads to many undesired consequences. The findings in this study, which investigated how nurses give CVC care, were discussed in the light of the literature.

The question, "What is applied to the skin after CVC dressing is cleaned with an antiseptic solution?", was correctly responded by only 16 nurses (see Table 2). The chlorhexidine impregnated transparent cover recommended in CVC dressings is stated to reduces CLABSI due to its waterproof gel structure containing chlorhexidine gluconate. Although it Published by Sciedu Press is important for nurses to make dressings with this material, the importance of this issue is also clearly stated in protocols/procedures/instructions. ${ }^{[34,35]}$ That the majority of the nurses responded incorrectly to this question suggests that this issue was not stated explicitly enough in the institution's CVC protocol/procedures/instructions.

The rate of correct responses by the nurses to the question, "Which of the antiseptic solutions used in CVC dressings is most effective?" was $52 \%(\mathrm{n}=105)$ (see Table 2$)$. In the literature, the use of chlorhexidine is recommended for the maintenance of the catheter area, and if there is a contraindication of its use, povidone-iodine of $10 \%$ or alcohol of $70 \%$ can also be used. Chlorhexidine is not available in all hos- 
pitals, and povidone-iodine and alcohol are easily available in every hospital. In the study, the use of povidone-iodine or alcohol instead of chlorhexidine is thought to stem from their low cost and availability. ${ }^{[36-40]}$ In a study on the knowledge levels of nurses about CCRBI in Poland, 50\% of nurses (n $=301$ ) reported that chlorhexidine should be used in CVC dressings. ${ }^{[17]}$

Also, the rate of correct responses by the nurses to the question "Which handwashing method do you use while giving care to a patient with CVC?" was $77.2 \%$ (see Table 2). Achieving hand hygiene in catheter care is extremely important to prevent the development of CLABSI, especially to reduce/eliminate the risk of cross-contamination between patients. Also, hand washing plays an important role in decreasing the complications of CVC as well as increasing the satisfaction level of the patients. As is reported in the literature, handwashing rates are higher among nurses than other healthcare workers, but it is not at the desired level. ${ }^{[11,14,18]}$ This is stated to be due to seeing hand washing less important than other procedures, lack of time due to heavy workload, and inadequate training in this issue. ${ }^{[40,41]}$ In a study conducted to determine the handwashing status of nurses working in the hospital, $92.9 \%$ of the nurses were found to be not trained in handwashing after graduation, and the most important reason affecting handwashing was the insufficient number of nurses per patient. ${ }^{[19]}$ The planning of nurses in health institutions in our country is conducted according to the "Ministry of Health Provincial Organization, Bed and Staff Standards Regulations for Inpatient Treatment Institutions". According to this regulation, at least one nurse is planned for the care of three patients in areas other than special units such as the operating room and intensive care unit. ${ }^{[20]}$ In this regard, one nurse provides care to fifteen patients in the 1200-bed institution where our study was conducted. In our study, the rate of handwashing by the nurses was not found at the desired level, which was thought to have stemmed from the high number of patients per nurse in the institution.

In our study, $54 \%$ of the nurses gave correct answers to the question "How do you administer TPN solutions through the CVC lumen?" Since candida species-bound CLABSI develops more in patients with CVC who are fed with TPN because the glucose can produce slime, a lumen should be allocated for TPN from the catheter in these patients. ${ }^{[4,11]}$ The determination of total parenteral and enteral nutrition and the complications that may occur during feeding are under the responsibility of the nurse, and the number of patients receiving TPN is higher in the intensive care units than in the clinics. ${ }^{[42]}$ In a study conducted by Batı and Özyürek, ${ }^{[16]}$ $77.9 \%$ of the nurses reported that a lumen should be re- served for TPN in CVC and that no other drugs should be administered here. In our study, the low number of correct answers was thought to have come from the participation of fewer intensive care nurses compared to the study of Batı and Özyürek. ${ }^{[16]}$

In our study, only 8 nurses responded correctly to the question, "How often should blood and blood product transfusion sets or infusion sets used for patients whose lipid emulsions are not supplied be changed in CVCs?" (see Table 2). Infusion sets used in patients not given blood, blood products or lipid emulsions should not be changed in less than 96 hours to avoid reproduction in the fluid, contamination, and colonization in the infusion sets. ${ }^{[44]}$ In a study measuring the "Knowledge Level of Nurses in Determining the Measures to Prevent CCRBI" by Labeau et al., ${ }^{[21]} 29 \%$ of the nurses ( $\mathrm{n}=$ 3,405 ) answered the replacement period of infusion sets used in patients without lipid emulsions as 96 hours. In another similar study, only $3.5 \%$ of the nurses were determined to give the correct answer by saying, "infusion fluid sets should change every 96 hours". ${ }^{[43]}$ In recent studies, the replacement period of infusion sets has been reported to increase from 72 to 96 hours. ${ }^{[22-24]}$ In another study in which "Nurses' Views on the Use of Research in the Professional Field" were determined, 406 of the 442 nurses were found to not follow the publication in the professional field. ${ }^{[25]}$ In other studies, nurses were observed to not benefit from the results of research in their professions and that this was attributed to not having enough time by them. ${ }^{[26,27]}$ Accordingly, the lack of knowledge of the nurses about the replacement period of the infusion sets was thought to have stemmed from the fact that they had not been following the literature and professional publications.

No significant relationship was found between the education level of the nurses and the knowledge scores they got from the questionnaire in our study (see Table 3). In a study on "Knowledge Levels on Hospital Infections" conducted by Köse et al., ${ }^{[28]}$ the level of knowledge was observed to increase as the education level of nurses increased. Similarly, in a study conducted by Diker, ${ }^{[2]}$ as the education level of nurses increased, knowledge scores regarding preventing hospital infections were determined to increase. As the level of education increases, the knowledge score for CVC care is expected to increase, as well. As a result, the increase in the level of education suggests that CLABSI can be decreased, too. This difference was thought to have stemmed from the fact that the nurses who were health vocational high schools graduates or had associate degree obtained more information about CVC than the nurses with an undergraduate or graduate degree, or that the nurses with an undergraduate or 
graduate degree were away from CVC care as they worked in the management position as a clinical officer.

In-service training is a type of training that is implemented to enable nurses to obtain relevant information, skills, and attitudes about their duties. ${ }^{[50]}$ In our study, the statistically significant $(p=.001)$ difference between the correct answers given by the nurses to the questions in the questionnaire related to CVC care depending on whether they received in-service training is important in showing that in-service training is really useful. The nurses were found to obtain this information mostly through in-service training (see Table 3 ). However, it has been stated in the literature that the availability of instructions, which have been developed in this field, in clinics and the provision of regular in-service training will increase compliance with catheter care rules and that training programs that increase the motivation of nurses will positively affect the quality of catheter use. ${ }^{[16,45]}$ The knowledge levels of nurses who participated in planned in-service training programs on CVC indications, complications, and use of CVC in an oncology hospital were higher than those who did not. ${ }^{[30]}$ In their study, Coopersmith et al. ${ }^{[46]}$ obtained findings supporting the idea that nurses' education had an important role in preventing catheter infections. In a study conducted by Özden et al., ${ }^{[31]}$ the knowledge scores of the nurses who received in-service training were found higher than those who did not. Our study was in line with the literature in this regard, and the knowledge gained by nurses from congresses, seminars, courses, and the literature, especially in-service training was considered to be important. For this reason, in-service training programs were organized in cooperation with the management at the institution where the study was conducted, and some interventions were implemented to overcome the lack of information.

In this study, 144 nurses were determined to apply CVC care in line with protocols/procedures. Nursing is a health discipline that consists of science and arts, planning of preventive and curative interventions and implementation of quality treatment interventions in line with the protocols/procedures/instructions determined by the institution, and at least a bachelor's degree. ${ }^{[48,49]}$ Protocols/procedures/instructions are prepared for the implementation of quality services by considering the patient benefit in line with the evidence-based practices related to hand hygiene, aseptic technique, barrier measures, skin antisepsis, catheter dressing, and catheter use. Also, the development of compulsory standards is among the goals. ${ }^{[47]}$ In a study, a handwashing protocol was developed to increase the handwashing rate of nurses $(n=12)$, and the compliance with handwashing was found to be $79 \%$ in nurses who applied the protocol, while it was found $66 \%$ in nurses who did not apply this protocol. ${ }^{[32]}$ In a study with 33 nurses in a nursing home, $87.5 \%$ of the nurses who applied the communication technique developed in accordance with a specific protocol stated that this helped them organize their thoughts and feel more confident in communication. ${ }^{[33]}$ The nurses who were aware of the existence of a protocol/procedures/instructions were thought to have answered CVC care questions correctly.

\section{CONCLUSIONS AND RECOMMENDATIONS}

We can recommend that because nurses who receive information about CVC and are aware of the existence of protocols/procedures/instructions get higher scores from the questions, in-service training programs on CVC care should be planned or nurses should be encouraged to participate in congresses/seminars/courses on this topic. Also, it should be made sure that all nurses implement the protocols/procedures/instructions which are available in the institution. Furthermore, to increase the effectiveness, their content regarding questions that nurses have difficulty answering should be extended more explicitly, this content should be included in the in-service training program, and feedback regarding this development should be obtained from nurses. The importance of this issue should be stated in orientation training programs for new nurses, and nurses who are aware of the existence of protocols/procedures/instructions should be appointed to their post.

Also, we recommended that practice standards based on evidence-based research results should be developed for all hospitals in the country that provide care for patients with $\mathrm{CVC}$ and that observational research should be carried out to determine nursing practices related to CVC care.

\section{Limitations of the study}

The fact that the study was conducted in a single hospital was accepted as the limitation of the study.

\section{CONFlicts of InTEREST Disclosure}

The authors declare they have no conflicts of interest. 


\section{REFERENCES}

[1] Smith RN, Nolan JP. Central venous catheters. BMJ. 2013; 347: 2832. PMid: 24217269. https://doi .org/10.1136/bmj .f6570

[2] Mahli A. Central Venous Catheterization. 2010 [Accessed at 11 January 2018]. Available from: http://med.gazi.edu.tr/posts/ download? id=20756

[3] Güleser GN, Taşçı S. Central Venous Catheters frequently used in Oncology and their Care. Firat University Health Sciences Journal of Medicine. 2009; 47-51.

[4] O'Grady NP, AlexanderM. Guidelines for the Prevention of Intravascular Catheter-Related Infections. Clinical Infectious Diseases. 2011; 52(9): 162-193. PMid: 21460264. https://doi.org/10.1093/ cid/cir 257

[5] Yalçın AN. Hospital Infections Cost Analysis. Hospital Infections: Protection and Control Symposium, Symposium Series No: 60. January 2008; 15-22.

[6] Frasca D, Dayhot-Fizelier C, Mimoz O. Prevention of central venous catheter-related infection in the intensive care unit. Critical Care. 2010. https ://doi .org/10.1007/978-1-4419-5562-3_22

[7] Holton D, Paton S, Conly J, et al. Central venous catheter-associated bloodstream infections occurring in Canadian intensive care units: A six-month cohort study. Canadian Journal of Infectious Diseases and Medical Microbiology. 2006; 17(3): 169-176. PMid: 18418495. https://doi.org/10.1155/2006/781735

[8] Çam R, Dönmez YC, Demir F. Analysis of Central Venous Catheters in Intensive Care Units and Complications that Develop. Journal of Intensive Care Nursing. 2008; 12(1-2): 17-22.

[9] Kostakoğlu U, Saylan S, Karataş M, et al. Cost Analysis and Evaluation of Nosocomial Infections in Intensive Care Units. Turkish Journal of Medical Sciences. 2016; 46(5): 1385-1392. PMid: 27966302. https://doi.org/10.3906/sag-1504-106

[10] Hakyemez IN, Yıldırmak MT, Çetmeli G, et al. The Frequency of Central Venous Catheter Related Infections, Active Microorganisms, and Risk Factors in a Tertiary Hospital. Abant Medical Journal. 2016; 5(2): 108-117. https://doi.org/10.5505/abantmedj 2016.80388

[11] Mankan T, Karakaşıkçı M. Knowledge Levels of Nurses on Prevention of Hospital Infections. Journal of Health Sciences. 2015; 4(1): 11-16.

[12] Menteş Ö, Yiğit T, Harlak A, et al. Catheter-Related Infections in the Surgical Intensive Care Unit. Gülhane Medical Journal. 2008; 50: 158-163.

[13] Ovayolu N, Güner İÇ, Karadağ G. Determination of Precautions Taken Before and After Application in Patients Administered Central Venous Catheter (CVC). Journal of Atatürk University School of Nursing. 2006; 9(3): 26-35.

[14] Yurttaş A, Kaya A, Engin R. Examination of Hand Hygiene Compliance and Hospital Infections in a University Hospital Intensive Care Unit. Journal of Health Sciences and Professions. 2016; 4(1): 1-7.

[15] Yüceer S, Demir SG. Prevention of Nosocomial Infections in the Intensive Care Unit and Nursing Practices. Dicle Medical Journal. 2009; 36(3): 226-232.

[16] Batı B, Özyürek P. Knowledge Levels of Nurses Working in the Intensive Care Unit about Central Venous Catheters. Journal of Intensive Care. 2015; 34-38. https ://doi.org/10.5152/dcbybd .2015 .828

[17] Dedunska K, Dyk D. Prevention of central venous catheter-associated bloodstream infections: A questionnaire evaluating the knowledge of the selected 11 evidence-based guidelines by Polish Nurses. Am J Infect Control. 2015; 43(12): 1368-71. PMid: 26307045. https://doi.org/10.1016/j.ajic.2015.07.022
[18] Garcell HG, Villanueva A. Direct Observation of Hand Hygiene Can Show Differences In Staff Compliance: Do We Need To Evaluate The Accuracy For Patient Safety? Qatar Medical Journal. 2017; 2 : 1-6. PMid: 28785534. https ://doi.org/10.5339/qmj . 2017.1

[19] Akyıl R, Uzun Ö. Determination of handwashing status of nurses working in hospital. Journal of Atatürk University School of Nursing. 2007; 10(2): 66-72.

[20] Türkmen E. Effects of Nurse Employment on Patient and Nurse Outcomes and Organizational Outputs. Hacettepe University Journal of Nursing Faculty. 2015; 69-80.

[21] Labeau S, Vandijck DM, Rello J, et al. Centers for Disease Control and Prevention guidelines for preventing central venous catheterrelated infection: results of a knowledge test among 3405 European intensive care nurses. Crit Care Med. 2009; 37(1): 320-323. PMid: 19050628. https://doi.org/10.1097/CCM.0b013e31 81926489

[22] Bishop L, Dougherty L, Bodenham A, et al. British Committee for Standards in Hematology (BCSH). International Journal of Laboratory Hematology. 2007; 29(10): 261-278. PMid: 17617077. https://doi.org/10.1111/j.1751-553X.2007.00931.x

[23] Marschall J, Mermel LA, Fakih M, et al. Strategies to prevent central line-associated bloodstream infections in acute care hospitals: 2014 update. Infect Control Hosp Epidemiol. 2014; 35: 753-71. PMid: 24915204. https://doi.org/10.1086/676533

[24] Rupp SM, Apfelbaum JL, Blitt C, et al. American Society of Anesthesiologists (ASA) Task Force on Central Venous Access. Practice Guidelines for central venous access. Anesthesiology. 2012; 116 : 539-573. PMid: 22307320. https ://doi .org/10.1097/ALN. Ob $013 e 31823 c 9569$

[25] Alp Yilmaz F. Determination of nurses' views on research and use of research. Thesis (Master's Degree). Cumhuriyet University Institute of Health Sciences Nursing Program, Sivas; 2006.

[26] Kocaman G, Seren S, Lash AA, et al. Barriers to Research utilisation by staff Nurses in a university hospital. Journal of Clinical Nursing. 2010; 19: 1908-1918. PMid: 20529164. https: //doi.org/10.1111/j.1365-2702.2009.03032.x

[27] Yava A, Tosun N, Çiçek H, et al. Validity and reliability study of the scale of barriers to the use of nursing research results. Gülhane Medical Journal. 2007; 49-72.

[28] Köse Y, Leblebici Y, Şen Akdere S, et al. Knowledge Status of Nurses Working in a Public Hospital about the Prevention of CatheterRelated Urinary System Infections. Ş.E.E.A.H. Medical Bulletin. 2016; 50(1): 70-79. https ://doi.org/10.5350/SEMB . 2015121 6103044

[29] Diker S. Determination of knowledge level of nurses working in hospitals in the central county of Uşak city. Master thesis, Afyon Kocatepe University Institute of Health Sciences Surgical Diseases Nursing Department, Afyon; 2003.

[30] Daniel B, Nagaraju B, Padmavagati GV, et al. A Study to Assess the Effectiveness of Structured Teaching Programme on Care of Patient With Central Venous Access Device Among Staff Nurses in Selected Oncology Hospital of Bangalore. International Journal of Medicine and Mfedical Science Research. 2013; 1(1): 001-01.

[31] Özden D, Çalışkan N. The knowledge level of Turkish nurses regarding implantable port catheter care. Jpn J Nurs Sci. 2012; 9(1): 1-8. PMid: 22583935. https://doi.org/10.1111/j.1742-792 4.2011.00177.x

[32] Fox C, Wavra T, Drake DA, et al. Use of a patient hand hygiene protocol to reduce hospital-acquired infections and improve nurses' hand washing. Am J Crit Care. 2015; 24(3): 216-24. PMid: 25934718 https://doi.org/10.4037/ajcc2015898 
[33] Renz SM, Boltz MP, Wagner LM, et al. Examining the feasibility and utility of an SBAR protocol in long-term care. Geriatr Nurs. 2013; 34(4): 295-301. PMid: 23721751. https ://doi.org/10.1016/j . gerinurse.2013.04.010

[34] Parienti JJ, Thirion M, Megarbane B, et al. Femoral vs. Jugular Venous Catheterization and Risk of Nosocomial Events in Adults Requiring Acute Renal Replacement Therapy: A Randomized Controlled Trial. JAMA. 20008; 299(20): 2413-22. PMid: 18505951. https://doi.org/10.1001/jama.299.20.2413

[35] Timsit JF, Schwebel C, Bouadma L, et al. Chlorhexidine-Impregnated Sponges and Less Frequent Dressing Changes for Prevention of Catheter-Related Infections in Critically Ill Adults: A Randomized Controlled Trial. JAMA. 2009; 301(12): 1231-1241. PMid: 19318651. https://doi.org/10.1001/jama.2009.376

[36] O'Grady NP, Alexander M, Burns LA, et al. Guidelines for the prevention of intravascular catheter-related infections. Am. J. Infect. Control. 2011; 39: 1-34.

[37] The Joint Commission. Preventing central line-associated bloodstream infections: a global challenge, a global perspective. 7 August 2019. Available from: https://www. jointcommission.org/as sets/1/18/CLABSI_Monograph.pdf

[38] Institute for Healthcare Improvement (IHI). How-to guide: prevent central line- associated bloodstream infections (CLABSI). 11 July 2019. Available from: http://www.ihi.org/Topics/Central LineInfection/Pages/default.aspx

[39] National Services Scothland (NHS). What are the key infection prevention and control recommendations to inform a central vascular catheter (CVC) maintenance care quality improvement tool? 11 July 2019. Available from: http://www.mhra.gov.uk/Publicatio ns/Safetywarnings/MedicalDeviceAlerts/CON197918

[40] Abdo NM, Fadhli MA. Improving hand hygiene compliance among healthcare workers in intensive care unit: an interventional study, Int. J. Community Med. Public Health. 2018: 5(9): 3747-3752. https://doi.org/10.18203/2394-6040.ijcmph20183558

[41] Yurttaş A, Kaya A, Engin R. Hand hygiene compliance and investigation of hospital infections in the intensive care unit of a university hospital. Journal of Health Sciences and Professions. 2017. Available from: https://dergipark.org.tr/hsp/issue/26227/11549 0

[42] Akbal Ergün Y, Demir H, Sağnak N. Study on Job Descriptions of Intensive Care Nurses. Journal of Intensive Care Nursing. 2007; 102-113.

[43] Chen S, Yao J, Chen J, et al. Knowledge of "Guidelines for the prevention of intravascular catheter-related infections-2011": A survey of intensive care unit nursing staffs in China. International Journal of Nursing Sciences. 2015; 2: 383-388. https://doi.org/10.1 016/j.ijnss.2015.10.002

[44] Central for Disease Control and Prevention. Guidelines for the Prevention of Intravascular Catheter - Related Infection. 2017 [Accessed at 2 Nov 2018]. Available from: http://www.cdc.gov/hicpac/p $\mathrm{df} /$ guidelines/bsi-guidelines-2011.pdf

[45] Blot K, Bergs J, Vogelaers D, et al. Prevention of central lineassociated blood stream infections through quality improvement interventions: a systematic review and metaanalysis. CID. 2014; 96-105. [Accessed at 08 March 2017]. PMid: 24723276. https : //doi.org/10.1093/cid/ciu239

[46] Coopersmith CM, Rebman TL, Zack JE, et al. The effect of training programs on reducing catheter-related bloodstream infections in the surgical intensive care unit. Journal of Intensive Care. 2002; 2 : 141-144.

[47] Schumacher M, Wagner HR. Central venous port system Associated thromboses outcome in 3498 implantation and literature review. German Medical Science. 2007; 5: 1612-1618.

[48] Terzi B, Kaya N. Nursing Care in Intensive Care Patient. Journal of Intensive Care. 2011; 1: 21-5. https ://doi .org/10.5152/dcby bd. 2011.05

[49] Akbal Ergün Y, Demir H, Sağnak N. Study on Job Descriptions of Intensive Care Nurses. Journal of Intensive Care Nursing. 2007; 102-113.

[50] Öztürk H, Savaşkan A. Problems experienced by nurses regarding in-service trainings and their expectations and suggestions, İ.Ü.F.N. Journal of Nursing. 2008; 16(61): 41-49. 